\title{
Toxicological Screening and Quantitation Using Liquid Chromatography/ Time-of-Flight Mass Spectrometry
}

\section{Linnet $\mathrm{K}^{*}$}

\author{
Department of Forensic Medicine, University of Copenhagen, Denmark
}

${ }^{*}$ Corresponding author: Linnet K, Professor, Section of Forensic Toxicology, Department of Forensic Medicine, Faculty of Health Sciences, University of Copenhagen, Denmark, Fax: +45353260 85, Tel: +45 353261 00,E-mail: kristian.linnet@sund.ku.dk

Citation: Linnet K (2013) Toxicological Screening and Quantitation Using Liquid Chromatography/Timeof-Flight Mass Spectrometry. J Forensic Sci Criminol 1(1): e101. doi: 10.15744/2348-9804.1.e101

Received Date: June 27, 2013 Accepted Date: July 29, 2013 Published Date: August 01, 2013

In recent years, an increasing number of new designerdrugs have increased the demands for general toxicological screening [1]. Limited screening based on immunoassays is commonly used in clinical toxicology, whereas more comprehensive approaches are common in forensic toxicology such as screening based on Gas or Liquid Chromatography (GC or LC) approaches [2]. The classic approach has been gas chromatography-Mass Spectrometry (GC-MS) combined with LC-diode-array detection (DAD) for systematic toxicological analysis. This setup has the advantage of covering a very broad spectrum of drugs and illicit substances when combined with library search facilities. However, the analytical sensitivity and specificity of LC-DAD may not be optimal. Thus, more sensitive and specific screening techniques based exclusively on LC combined with mass spectrometry have gained popularity. Multi-target screening and quantitation methods based on LC-tandem mass spectrometry (MS/MS) may provide detection of hundred or more compounds [3]. Using ion-trap MSn detection, several hundred compounds can be detected [4]. A more extended screening is possible using time-of-flight (TOF) mass spectrometry, which is a highresolution mass spectrometry technique that detects drugs on the basis of their exact mass. Using this technique, scanning is performed over all masses for low molecular drugs, and detected signals can be related to a library of exact drug masses. Retention time and fragmentation pattern contribute to the identification. In principle, it is possible to screen for thousands of compounds, although issues related to software capabilities may limit the number of compounds to several hundred in daily practice [5-7].

Having detected compounds in toxicology, quantitation is usually also desired. Several techniques are available, e.g. GC, LC-DAD, GC-MS and LC-MS/MS. LC-MS/MS is generally regarded as the optimal approach, having unsurpassed sensitivity, specificity and dynamic range [3]. However, LC-TOF-MS may not only be used for screening but also for quantitation as recently investigated by several authors [8-10]. The dynamic range and sensitivity may not match those of LC-MS/MS, but may still be acceptable. Liquid chromatography-mass spectrometry equipment is generally expensive, so a combination of screening and quantitation by the same equipment is both practical and of advantage from an economical point of view, in the paper by Dalsgaard, et al. [11], in this issue of the journal, quantitation of common drugs of abuse in blood by LC-TOF-MS is considered.

\section{References}

1. Favretto D, Pascali JP, Tagliaro F (2013) New challenges and innovation in forensic toxicology: focus on the "New Psychoactive Substances". J Chromatogr A 1287: 84-95.

2. Maurer HH (2013) What is the future of (ultra) high performance liquid chromatography coupled to low and high resolution mass spectrometry for toxicological drug screening? J Chromatogr A 1292: 19-24.

3. Peters FT (2011) Recent advances of liquid chromatography-(tandem) mass spectrometry in clinical and forensic toxicology. Clin Biochem 44: 5465.

4. Dresen S, Ferreiros N, Gnann H, Zimmermann R, Weinmann W (2010) Detection and identification of 700 drugs by multi-target screening with a 3200 Q TRAP LC-MS/MS system and library searching. Anal Bioanal Chem 396: $2425-34$

5. Ojanpera I, Kolmonen M, Pelander A (2012) Current use of highresolution mass spectrometry in drug screening relevant to clinical and forensic toxicology and doping control. Anal Bioanal Chem 403: 1203-20.

6. Broecker S, Herre S, Wust B, Zweigenbaum J, Pragst F (2011) Development and practical application of a library of CID accurate mass spectra of more than 2,500 toxic compounds for systematic toxicological analysis by LCQTOF-MS with data-dependent acquisition. Anal Bioanal Chem 400: 101-17.

7. Polettini A, Gottardo R, Pascali JP, Tagliaro F (2008) Implementation and performance evaluation of a database of chemical formulas for the screening of pharmaco/toxicologically relevant compounds in biological samples using electrospray ionization-time-of-flight mass spectrometry. Anal Chem 80: 3050-57.

8. Gonzalez-Marino I, Quintana JB, Rodriguez I, Gonzalez-Diez M, Cela R (2012) Screening and selective quantification of illicit drugs in wastewater by mixed-mode solid-phase extraction and quadrupole-time-of-flight liquid chromatography-mass spectrometry. Anal Chem 84: 1708-17.

9. Saleh A, Stephanson NN, Granelli I, Villen T, Beck O (2012) Evaluation of a direct high-capacity target screening approach for urine drug testing using liquid chromatography-time-of-flight mass spectrometry. J Chromatogr B Analyt Technol Biomed Life Sci 909: 6-13. 
10. Broecker S, Herre S, Pragst F (2012) General unknown screening in hair by liquid chromatography-hybrid quadrupole time-of-flight mass spectrometry (LC-QTOF-MS). Forensic Sci Int 218: 68-81.
11. Dalsgaard PW, Rode AJ, Rasmussen BS, Bjork MK, Petersen DI, et al. (2013) Quantitative Analysis of 30 Drugs in Whole Blood by SPE and UHPLC-TOFMS. J Forensic Sci Criminol 1: 1-7.

\footnotetext{
Submit your next manuscript to Annex Publishers and benefit from:

> Easy online submission process

> Rapid peer review process

> Online article availability soon after acceptance for Publication

> Open access: articles available free online

> More accessibility of the articles to the readers/researchers within the field

> Better discount on subsequent article submission

Submit your manuscript at

http://www.annexpublishers.com/paper-submission.php
} 